\title{
Deep Intraseasonal Variability in the Central Equatorial Atlantic
}

\author{
FRANZ PHILIP TUCHEN \\ GEOMAR Helmholtz Centre for Ocean Research Kiel, Kiel, Germany \\ Peter Brandt AND Martin Claus \\ GEOMAR Helmholtz Centre for Ocean Research Kiel, and Christian-Albrechts-Universität zu Kiel, \\ Kiel, Germany \\ REBECCA HUMMELS \\ GEOMAR Helmholtz Centre for Ocean Research Kiel, Kiel, Germany
}

(Manuscript received 23 March 2018, in final form 27 September 2018)

\begin{abstract}
Besides the zonal flow that dominates the seasonal and long-term variability in the equatorial Atlantic, energetic intraseasonal meridional velocity fluctuations are observed in large parts of the water column. We use 15 years of partly full-depth velocity data from an equatorial mooring at $23^{\circ} \mathrm{W}$ to investigate intraseasonal variability and specifically the downward propagation of intraseasonal energy from the near-surface into the deep ocean. Between 20 and $50 \mathrm{~m}$, intraseasonal variability at $23^{\circ} \mathrm{W}$ peaks at periods between 30 and 40 days. It is associated with westward-propagating tropical instability waves, which undergo an annual intensification in August. At deeper levels down to about $2000 \mathrm{~m}$ considerable intraseasonal energy is still observed. A frequency-vertical mode decomposition reveals that meridional velocity fluctuations are more energetic than the zonal ones for periods $<50$ days. The energy peak at 30-40 days and at vertical modes $2-5$ excludes equatorial Rossby waves and suggests Yanai waves to be associated with the observed intraseasonal energy. Yanai waves that are considered to be generated by tropical instability waves propagate their energy from the near-surface west of $23^{\circ} \mathrm{W}$ downward and eastward to eventually reach the mooring location. The distribution of intraseasonal energy at the mooring position depends largely on the dominant frequency and the time, depth, and longitude of excitation, while the dominant vertical mode of the Yanai waves plays only a minor role. Observations also show the presence of weaker intraseasonal variability at $23^{\circ} \mathrm{W}$ below $2000 \mathrm{~m}$ that cannot be associated with tropical instability waves.
\end{abstract}

\section{Introduction}

The equatorial Atlantic Ocean is characterized by energetic zonal currents that vary dominantly on seasonal to interannual time scales (Brandt et al. 2016; Claus et al. 2016). In contrast, meridional velocity exhibits a spectral peak on intraseasonal time scales, that is, periods of 10-50 days (Athie and Marin 2008; Bunge et al. 2008; Ascani et al. 2015). It has been shown that intraseasonal meridional velocity variability is forced either by the instability of the mean wind-driven circulation of the equatorial Atlantic and its low-frequency variability, thereby generating tropical instability waves (TIWs), or directly by meridional wind fluctuations at the equator (Garzoli 1987;

Corresponding author: Franz Philip Tuchen, ftuchen@geomar.de
Weisberg and Weingartner 1988; Athie and Marin 2008; von Schuckmann et al. 2008). Intraseasonal zonal velocity variability, however, is mainly forced by fluctuations of the zonal wind stress at the equator exciting intraseasonal Kelvin or Rossby waves or by the reflection of equatorial and off-equatorial Rossby waves at the western boundary (Polo et al. 2008).

TIWs appear to zonally propagate near the surface and are often described as quasi-monthly fluctuations of sea surface temperature (SST) or sea surface height anomalies being common to all tropical oceans (Steger and Carton 1991). Atlantic TIWs are generally characterized by periods of 20-60 days, zonal wavelengths of $600-1200 \mathrm{~km}$, and westward phase speeds of $20-60 \mathrm{~cm} \mathrm{~s}^{-1}$ (e.g., Weisberg and Weingartner 1988; Steger and Carton 1991; von Schuckmann et al. 2008). At shorter periods 
( $\sim 14$ days), biweekly meridional wind variability directly forces intraseasonal oceanic variability, which is, however, mainly restricted in the equatorial Atlantic to longitudes east of $10^{\circ} \mathrm{W}$ (e.g., Garzoli 1987; Athie and Marin 2008).

Atlantic TIWs are generated by either barotropic or baroclinic instability in the Northern Hemisphere but almost exclusively by baroclinic instability in the Southern Hemisphere (Grodsky et al. 2005; von Schuckmann et al. 2008). Barotropic instability arises from the horizontal shear of zonal currents, that is, between the Equatorial Undercurrent (EUC) and the northern South Equatorial Current (nSEC) and between the nSEC and the North Equatorial Countercurrent (NECC) (Jochum et al. 2004; von Schuckmann et al. 2008), whereas baroclinic instability was found to be associated with SST fronts (Yu et al. 1995) and with the vertical shear of the nSEC and the central South Equatorial Current (cSEC) (von Schuckmann et al. 2008).

The horizontal velocity shear between the equatorial zonal currents exhibits an annual cycle. When the southeast trade winds start to intensify in June/July, the equatorial zonal currents accelerate and the associated horizontal shear strengthens. At the same time, the vertical shear within the nSEC and cSEC enhances. Stronger horizontal and vertical shear lead to an intensification of barotropic and baroclinic instability causing the generation of intensified TIWs. Simultaneously, the Atlantic cold tongue develops in response to the strengthening of the southeast trade winds, bringing cold thermocline water closer to the surface and enhancing vertical mixing at the base of the shallow equatorial mixed layer. A sharp meridional SST gradient develops north of the equator, which has been proposed as an additional energy source for the TIWs (Yu et al. 1995). The annual intensification of TIW activity occurs in boreal summer (Weisberg and Weingartner 1988; Athie and Marin 2008). Besides a pronounced annual cycle, significant interannual variability of intraseasonal SST variance is observed from satellite data (Wu and Bowman 2007), which at least partly can be related to the variability in the wind forcing and resulting current shear (Perez et al. 2012).

While the generation of TIWs is mostly confined to the near-surface layers (i.e., the upper $50 \mathrm{~m}$ ), enhanced intraseasonal variability can be observed down to greater depths (e.g., Bunge et al. 2008). A large part of the intraseasonal energy that is generated by instability close to the surface propagates into the deep ocean as downward- and eastward-propagating beams of Yanai waves (Ascani et al. 2010). Ascani et al. (2015) proposed this so-called deep equatorial intraseasonal variability (DEIV) to be the major driver for the deep equatorial circulation (DEC), which includes the equatorial deep jets (EDJs) and the equatorial intermediate currents. It could be shown that the DEIV, after being generated by instability of the upper-ocean circulation and propagation away from its source, finally rectifies into the mean and low-frequent DEC (Ascani et al. 2015). However, a realistic simulation of the DEC largely depends on the amplitude and structure of the DEIV, which previously could not be evaluated owing to insufficient observations of the DEIV. Recently, Greatbatch et al. (2018) were able to show that intraseasonal waves, which are excited by the instability of the near-surface wind-driven circulation, feed energy into the EDJs to maintain them against dissipation. This mechanism is in general agreement with the simulation performed by Ascani et al. (2015), in which a time-independent wind forcing results in a mean wind-driven circulation, which becomes unstable and generates TIWs. These TIWs are the source of DEIV, which provide energy for the EDJs and its regular interannual oscillations. Hua et al. (2008) also linked intraseasonal variability to the generation and maintenance of the DEC, but instead of instability generated near the surface, they proposed that the variability originates from fluctuations of the cross-equatorial western boundary current (see also D'Orgeville et al. 2007). Besides their influence on the DEC, Jochum and Malanotte-Rizzoli (2004) showed that TIWs contribute to the forcing of the South Equatorial Undercurrent (SEUC), while Hüttl-Kabus and Böning (2008) showed the importance of TIWs for driving both the North Equatorial Undercurrent (NEUC) and the SEUC.

To date, observational studies of intraseasonal fluctuations have been based either on satellite data (e.g., Steger and Carton 1991; Athie and Marin 2008; Polo et al. 2008), which mainly focused on the near-surface ocean, or on moored acoustic Doppler current profiler (ADCP) data (Qiao and Weisberg 1995; Grodsky et al. 2005; von Schuckmann et al. 2008) and moored singlepoint current meter measurements with observational periods of up to 5 years (Weisberg and Weingartner 1988; Bunge et al. 2008). In this study, we present partly full-depth velocity data from an equatorial mooring at $23^{\circ} \mathrm{W}$ spanning the time period from 2001 to 2016 . The temporal and vertical coverage of the $23^{\circ} \mathrm{W}$ dataset is unique and enables us to investigate the DEIV, which so far was largely limited to numerical studies.

This study is structured as follows: Section 2 provides an overview of the mooring data, while in section 3 the methods that were used in the analysis are explained. The results are divided into the mean statistics of intraseasonal variability at $23^{\circ} \mathrm{W}$ in section 4 and seasonal and interannual variations of intraseasonal variability in 


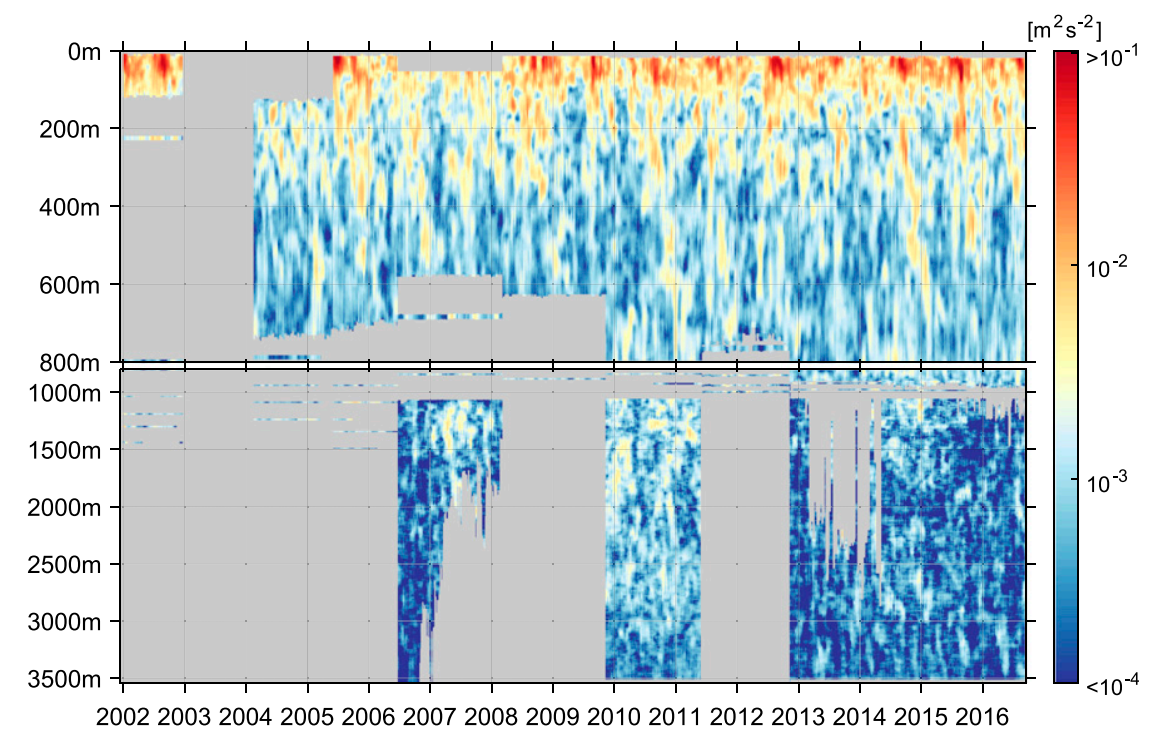

FIG. 1. Meridional kinetic energy $(1 / 2) v^{2}$ from the mooring on the equator at $23^{\circ} \mathrm{W}$ from December 2001 to September 2016. Tick marks along the time axis denote the beginning of the year. Single-point measurements are extended by $5 \mathrm{~m}$ from their nominal depth in both directions for better visualization. Gray areas show missing data. Note the different vertical scaling above and below $800 \mathrm{~m}$ and the logarithmic color scale. For better visualization the meridional kinetic energy is smoothed with a running box median of 60 days and $10 \mathrm{~m}$.

section 5. Eventually, section 6 provides a discussion and summary of the results.

\section{Moored velocity data}

Meridional and zonal velocity observations were obtained from 10 consecutive current meter moorings deployed on the equator at $23^{\circ} \mathrm{W}$ from December 2001 to September 2016 (except for one period between December 2002 and February 2004, when no mooring was installed). The used dataset is an update of Brandt et al. (2016) and Claus et al. (2016) extended by the two most recent mooring deployments and additional data before 2004, including ADCP and single-point current meter data from December 2001 to December 2002 (see Grodsky et al. 2005) and single-point measurements between 2001 and 2006 (see Bunge et al. 2008).

Since February 2004, the upper part of the water column was covered by two ADCPs: one upwardlooking ADCP, which was installed just below the EUC at $100-230 \mathrm{~m}$ and a lower ADCP, which was either looking downward from just below the upper ADCP or looking upward from 600- to 650-m depth. Few additional single-point current meters were usually installed between 600 and $1000 \mathrm{~m}$, although several instruments before 2006 were located at larger depths between 1000 and $1500 \mathrm{~m}$ (Fig. 1). ADCP and singlepoint current meter data were 40-h low-pass-filtered to detide the velocity data and subsampled to a $12-\mathrm{h}$ resolution.

Since June 2006, the depth range between 1000 and $3500 \mathrm{~m}$ was covered by a McLane Moored Profiler (MMP). Unfortunately, the profiler sampled data only during 5 out of 7 mooring periods ( 3 times whole-depth coverage). During the remaining two mooring periods, the instrument failed and no data could be recovered. The MMP was programmed to sample pairs of profiles every 3-5 days, depending on the planned duration of the mooring and battery life. No further temporal filtering was applied to the velocity data from the MMP since the sampling frequency is well below tidal frequencies. The acquired velocity dataset is complemented by full-depth lowered ADCP profiles, which were taken during the mooring service cruises. Figure 1 provides an overview of the data distribution by showing the time series of specific kinetic energy (or kinetic energy per unit mass) $(1 / 2) v^{2}$ derived from the meridional velocity with a running box median of 60 days and $10 \mathrm{~m}$ applied on it, while Fig. 2 shows the meridional velocity for an exemplary time period from June 2006 to March 2008 with two single-point measurements between the ADCP range above and the MMP range below.

To date, zonal velocity data of this time series have been used to study the EDJs (Bunge et al. 2008; Brandt et al. 2011; Claus et al. 2016; Greatbatch et al. 2018) and 


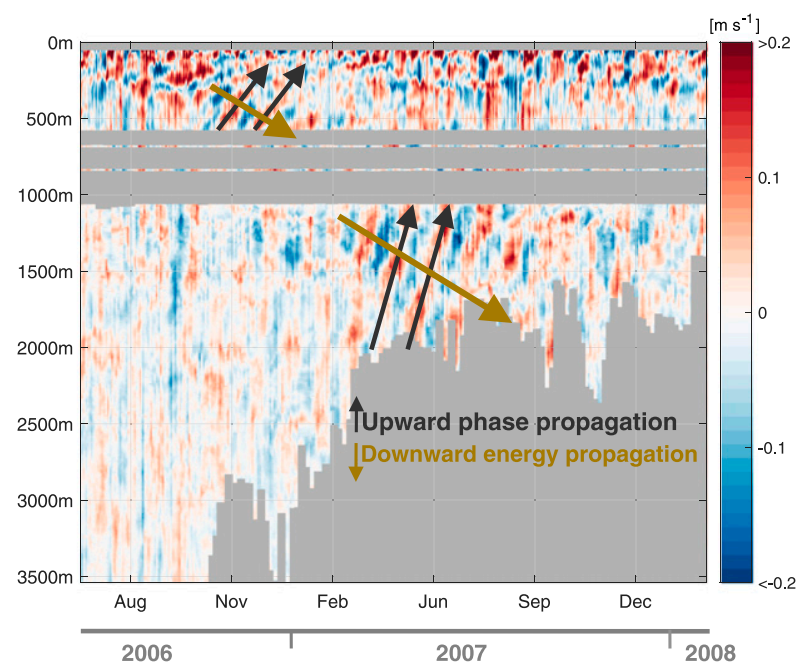

FIG. 2. Meridional velocity from the mooring on the equator at $23^{\circ} \mathrm{W}$ from June 2006 to March 2008. Tick marks along the time axis denote the first day of the month. Positive (negative) values represent northward (southward) velocities, whereas gray areas show missing data. Single-point measurements are extended by $5 \mathrm{~m}$ from their nominal depth in both directions for better visualization. Also represented schematically are upward phase and downward energy propagation in two different depth ranges.

the EUC (Giarolla et al. 2005; Brandt et al. 2014, 2016). Meridional velocity data have been used by Grodsky et al. (2005) to examine the contribution of TIWs to the mixed layer heat and energy budget, by Giarolla et al. (2005) to analyze meridional variations of the EUC associated with TIWs, by Bunge et al. (2008) to describe deep intraseasonal variability, and by von Schuckmann et al. (2008) to investigate the generation mechanisms of TIWs in combination with model simulations. Since then, the dataset has massively enlarged in time and depth coverage.

\section{Methods}

As a first step, data from different instruments moored on the equator at $23^{\circ} \mathrm{W}$, which vary in their vertical resolution and their sampling frequency, were interpolated onto a uniform depth and time grid, resulting in a data grid resolution of $12 \mathrm{~h}$ in time and $1 \mathrm{~m}$ in depth (see Fig. 2). If the temporal gaps between two velocity values at the same depth were less than 10 days, they were filled by interpolation.

\section{a. Lomb-Scargle periodogram}

Despite the remarkable coverage of the time series, periods of missing data occur and have to be treated with care considering spectral analysis or the decomposition into vertical modes, which will be explained later in this section. The approach of Scargle (1982) calculates the power spectral density (PSD) of a time series with nonuniformly distributed data over time orlike in this case-data gaps. For a given angular frequency $\omega=2 \pi f$ the periodogram $P$ is estimated by

$$
P(\omega, z)=\frac{1}{2 \sigma^{2}}\left(\frac{\left\{\sum_{i} v\left(t_{i}, z\right) \cos \left[\omega\left(t_{i}-\tau\right)\right]\right\}^{2}}{\sum_{i} \cos ^{2}\left[\omega\left(t_{i}-\tau\right)\right]}+\frac{\left\{\sum_{i} v\left(t_{i}, z\right) \sin \left[\omega\left(t_{i}-\tau\right)\right]\right\}^{2}}{\sum_{i} \sin ^{2}\left[\omega\left(t_{i}-\tau\right)\right]}\right) .
$$

Here $v$ is the meridional velocity at a particular depth $z$ and time $t$ with the subscript referring to the specific time step $i$ of the time series, while $\sigma^{2}$ refers to the variance of the time series. The $\tau$ represents the time delay at which the sinusoids would be mutually orthogonal, defined by

$$
\tan (2 \omega \tau)=\frac{\sum_{i} \sin \left(2 \omega t_{i}\right)}{\sum_{i} \cos \left(2 \omega t_{i}\right)} .
$$

This approach allows us to calculate periodograms at each depth for a set of orthogonal frequencies, equivalent to those of a discrete Fourier transform of a complete time series without gaps. In an attempt to quantify the uncertainty of this method introduced by the data gaps, the periodogram was recalculated for a subset in time and depth space for which full data coverage was given and compared to the periodogram of the same subset attributed with artificially introduced data gaps (not shown). The differences between these periodograms are only marginal compared to the amplitude of the periodogram, and the main features discussed within this study are robust.

\section{b. Modal decomposition}

As described in Philander (1978), standing vertical modes are an appealing way to describe the vertical structure of the ocean; especially in the particular case of a single mooring, when no knowledge about the zonal wavenumber or meridional structure is available. Alternatively, vertically propagating latitudinal modes can be used as well to describe vertically propagating 
equatorial waves, but this method requires knowledge of the horizontal structure involved. Here, we are using the first method of standing vertical modes, which, in this framework, results in a clear separation of the frequency bands in which inertia-gravity waves and Rossby waves may exist for a given vertical mode. The cutoff frequency of the gravest equatorial Rossby wave is given by $\omega_{R}=\sqrt{\beta c_{n}}(1-\sqrt{1 / 2})($ with $\beta$ the latitudinal variation in the Coriolis parameter on the equator and $c_{n}$ the internal gravity wave speed of the vertical mode $n$ ), above which energy in the meridional component cannot be associated with Rossby waves (Olbers et al. 2012). Analogously, equatorial inertia-gravity waves are limited to frequencies above $\omega_{G}=\sqrt{\beta c_{n}}(1+\sqrt{1 / 2})$ (Olbers et al. 2012). Hence, $\omega_{R}$ is always smaller than $\omega_{G}$ for a given vertical mode $n$.

To connect the vertical structure of zonal $u$ and meridional $v$ velocity to equatorial wave dynamics, both velocity components were fit to a set of standing vertical modes, which were calculated from a full-depth $(0-4500 \mathrm{~m})$ mean buoyancy frequency profile $N=\sqrt{-\left(g / \rho_{0}\right) d \rho(z) / d z}$ with gravitational acceleration $g$, a reference density $\rho_{0}$, and density as a function of the vertical coordinate $\rho(z)$. The mean $N^{2}$ profile was derived from 47 CTD casts taken on the equator at $23^{\circ} \mathrm{W}$ [see Claus et al. (2016) for a more detailed description]. Based on the mean $N^{2}$ profile, structure functions $\hat{p}_{n}$ for a particular mode $n$ can be derived by solving the eigenvalue problem (see Gill 1982):

$$
\frac{d}{d z}\left(\frac{1}{N^{2}} \frac{d \hat{p}_{n}}{d z}\right)+\frac{1}{c_{n}^{2}} \hat{p}_{n}=0,
$$

with boundary conditions given by

$$
\frac{1}{N^{2}} \frac{d \hat{p}_{n}}{d z}=0(z=H), \quad \hat{p}_{n}+\frac{g}{N^{2}} \frac{d \hat{p}_{n}}{d z}=0(z=0) .
$$

The solution is an orthogonal set of vertical structure functions $\hat{p}_{n}$ and constants $c_{n}$, which represent the gravity wave speed for the vertical mode $n$. The amplitude of each vertical structure function is normalized as follows:

$$
\int_{-H}^{0} \hat{p}_{n}^{2} d z=H
$$

After subtracting the time mean profile from the original velocity data, both time series ( $u$ and $v$ ) are mapped onto a grid with a temporal resolution of 5 days and a vertical resolution of $10 \mathrm{~m}$ in order to reduce computational costs. Since the set of normal modes is derived from a mean buoyancy frequency profile with a vertical range of $4500 \mathrm{~m}$, it is necessary to extrapolate the moored velocity field in the vertical direction in order to constrain the fit in the vertical direction. For that purpose, the deepest value of the time series at each time step is extended down to $4500 \mathrm{~m}$, but only if the measurements were taken below $3000 \mathrm{~m}$. As an alternative the moored velocities were extrapolated by 0 down to 4500-m depth. However, the results of this study are not sensitive to the choice of extrapolation toward 4500-m depth.

With a combination of vertical normal mode $n=0$, $1,2, \ldots, 25$ and angular frequency $\omega_{j}=\omega_{1}, \omega_{2}, \ldots, \omega_{K}$, based on the same set of frequencies as used for the calculation of the periodograms, a fitting model is set up by the product of a temporal sine and analogously cosine function with an angular frequency $\omega_{j}(j=1,2, \ldots, K)$ with the vertical structure function. The barotropic mode $(n=0)$ is also included with $\hat{p}_{0}(z)=1$ being constant with depth. The actual fitting is performed by searching the scalar amplitudes $a_{n, j}$ and $b_{n, j}$, which solve the system of linear equations via an optimization process:

$$
\begin{aligned}
& \hat{p}_{n}(z) \sin \left(\omega_{j} t\right) a_{n, j}=u(z, t), \quad \text { and } \\
& \hat{p}_{n}(z) \cos \left(\omega_{j} t\right) b_{n, j}=u(z, t),
\end{aligned}
$$

yielding the amplitudes $a_{n, j}$ for sine and $b_{n, j}$ for cosine fitting, respectively. The amplitude $A_{n, j}$ of the spectrum in normal mode space is derived by calculating the modulus $A_{n, j}=\sqrt{a_{n, j}^{2}+b_{n, j}^{2}}$. Note that in (5) $u$ is a placeholder for either the zonal or meridional velocity. After the fitting, a reconstruction of the velocity field based on the used frequency-normal mode combination is calculated and subtracted from the velocity field before the next combination of $\left(\omega_{j}, \hat{p}_{n}\right)$ is chosen and fit to the residual.

Unfortunately, the gaps in the velocity data disturb the orthogonality of the frequency-normal mode decomposition and lead to uncertainties in the magnitude and distribution of the amplitude. To quantify and minimize the influence of data gaps, different combinations of frequency and normal mode are used in a random order. This procedure is repeated for 1000 permutations, which are then used to build a mean amplitude spectrum (averaged over all permutations). The spread of different solutions around the mean is taken as a measure of the uncertainty of the amplitude of the frequency-normal mode spectrum introduced by data gaps. For each permutation, the amplitude spectrum in frequency-normal mode space is first squared and then integrated over all baroclinic modes providing 1000 variance spectra from which a $95 \%$ confidence range at each frequency is calculated by excluding the highest and lowest $2.5 \%$ of the obtained values. 

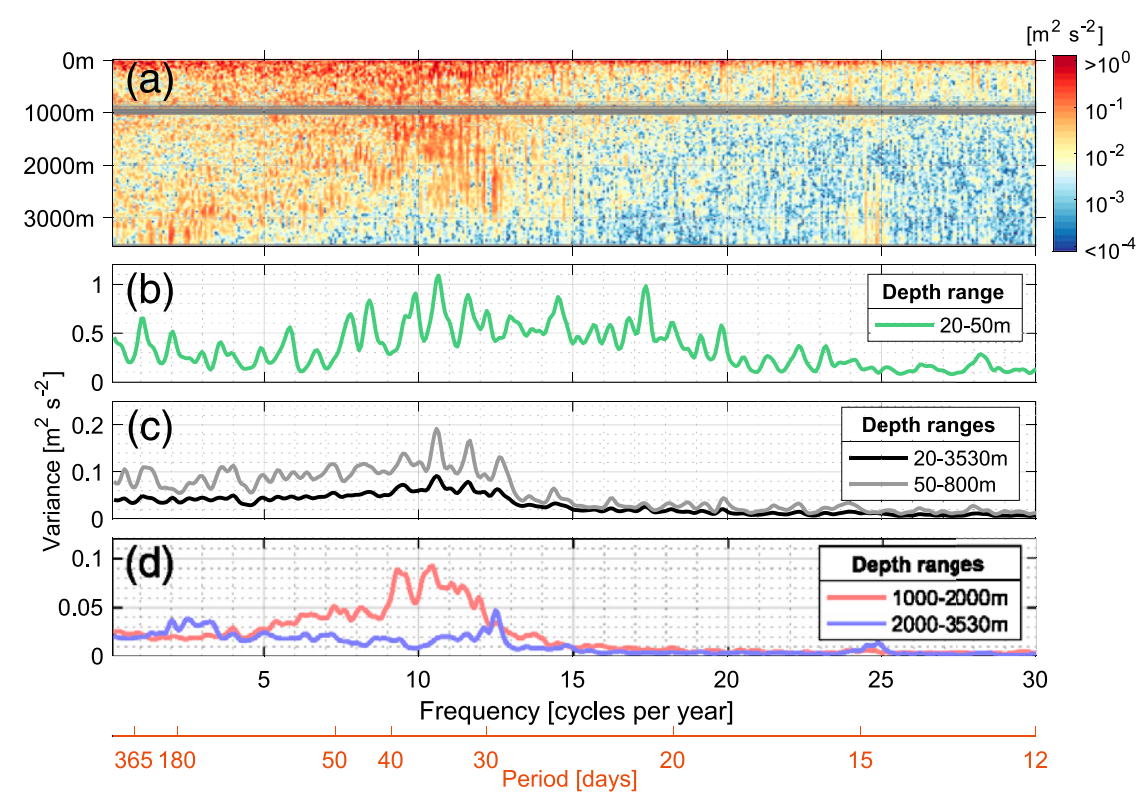

FIG. 3. (a) Lomb-Scargle periodogram [(1)] of meridional velocity from the mooring on the equator at $23^{\circ} \mathrm{W}$ as a function of depth. Too sparsely sampled depths are marked gray. Note the logarithmic color scale. (b)-(d) Vertically averaged periodograms for different depth ranges (see legends). Note the differently scaled $y$ axes.

The mean amplitude for a given frequency and vertical mode of 1000 permutations is, on average, smaller (higher) than the 97.5 (2.5) percentile value of the corresponding distribution by a factor of 1.8 (4.3).

\section{c. Yanai beams}

Moored meridional velocity data regularly exhibit upward propagation of phase (Fig. 2), which implies downward energy propagation, according to linear wave theory (Gill 1982). It is suggested that the downward propagation of energy is accomplished by downwardpropagating beams of intraseasonal Yanai waves (e.g., Ascani et al. 2010). Here, the calculation of Yanai beams is based on the theoretical work of McCreary (1984), who showed that for an angular frequency $\omega$ and a buoyancy frequency profile $N(z)$ the following relation holds for the angle of a downward propagating Yanai beam $\gamma$ :

$$
\tan \gamma=\frac{c_{g z}}{c_{g x}}=-\frac{\omega}{N(z)}
$$

where $c_{g x}=c_{n} /\left[1+\left(\beta c_{n} / \omega^{2}\right)\right]$ (Olbers et al. 2012) is the zonal and $c_{g z}$ the vertical group velocity of a Yanai wave. Note that for an upward-propagating Yanai beam only the sign changes. Within the framework of standing vertical modes, vertical propagation can only be achieved by the superposition of different vertical modes; the use of a limited number of vertical modes represents thus an approximation of the vertical beam propagation. The gravity wave speed $c_{n}$, which defines the group velocity, might vary for different beams depending on the dominant vertical mode contributing to the beam forming.

\section{Mean statistics of intraseasonal variability}

The equatorial Atlantic circulation is characterized by low-frequency zonal velocity variability, that is, seasonal (semiannual and annual) and interannual (4.5-yr period of EDJs) variability (Brandt et al. 2016; Claus et al. 2016). In contrast, meridional velocity variability is most energetic in the intraseasonal frequency band with periods shorter than $\sim 50$ days.

On the basis of almost 15 years of partly full-depth velocity measurements, a periodogram of meridional velocity data (Fig. 3a) following the approach of Scargle (1982) reveals that the highest variability is close to the surface $(20-50 \mathrm{~m})$ and most pronounced within a frequency range of 7-20 cycles per year (equivalent to periods of 18-52 days) reaching values between 0.5 and $1 \mathrm{~m}^{2} \mathrm{~s}^{-2}$ (Fig. 3b). Between 50 and $800 \mathrm{~m}$ (Fig. 3c), maximum values are about one order of magnitude smaller $\left(0.2 \mathrm{~m}^{2} \mathrm{~s}^{-2}\right)$ compared to the near-surface layer (Fig. 3b) and most elevated below 13 cycles per year (periods larger than 28 days). Here, the three most pronounced frequencies are 10.5, 11.6, and 12.8 cycles per year (34.8, 31.5, and 28.5 days, respectively). Between 1000 and $2000 \mathrm{~m}$, the frequency band of the 
highest intraseasonal variability becomes more confined between 9 and 12 cycles per year (30-41 days) (Fig. 3d), while reaching about half the values of the layer above. Figure $3 \mathrm{~d}$ also shows that below $2000 \mathrm{~m}$ the intraseasonal peak vanishes, and three rather distinct signals emerge: first, a range between 2 and 4 cycles per year (periods of 90-180 days) close to a depth of $3500 \mathrm{~m}$; second, a peak at 12.5 cycles per year (a period of 29.2 days), which is distinguished more clearly between 2000 and $3000 \mathrm{~m}$ (Fig. 3a); and last, at about 25 cycles per year (a period of 14 days) again close to $3500 \mathrm{~m}$. The first signal represents variability on seasonal time scales and could be associated with zonally propagating equatorial Kelvin waves, which generate meridional motions when encountering topography like, for example, the MidAtlantic Ridge (McPhaden and Gill 1987). The change in the characteristics of intraseasonal variability below $2000 \mathrm{~m}$ in comparison to the layers above suggests a different generation mechanism of the variability for these layers. In the following, we will focus on the intraseasonal energy observed above $2000 \mathrm{~m}$ and discuss the deeper variability later.

We have shown that specific kinetic energy of the meridional velocity in the upper $2000 \mathrm{~m}$ is generally enhanced within the intraseasonal frequency band. The peak frequency, however, might change with depth. When considering downward-propagating equatorial wave beams as a source for the observed DEIV, one would observe the signature of different beams at $23^{\circ} \mathrm{W}$, which are excited away from the mooring and reach it at a particular depth with a certain time lag. To infer the potential equatorial wave type with which the observed intraseasonal variability can be associated, a frequencyvertical mode decomposition of both horizontal velocity components was carried out. Linear equatorial wave dynamics imply that within the intraseasonal frequency band the following wave types exist: Kelvin waves, Rossby waves, Yanai waves, and inertia-gravity waves. Kelvin waves can be excluded as a source of intraseasonal meridional velocity variability since they are strictly associated with a zonal velocity component along the equator. Yanai waves theoretically exist at all frequencies but change the direction of their phase speed toward higher frequencies. A strict separation between Rossby, Yanai, and inertia-gravity waves from moored observations at one location is not possible since the zonal wavenumber remains unknown. However, a frequency range exists, for which Rossby and inertiagravity waves can be excluded (see section $3 b$ ) and meridional velocity variability in between their cutoff frequencies can only be associated with Yanai waves. Note that in the framework of vertically propagating latitudinal modes, inertia-gravity waves are not restricted by a cutoff frequency (Philander 1978). The amplitude spectra derived by fitting zonal and meridional velocities to a set of vertical normal modes and a set of orthogonal frequencies are shown in Figs. $4 \mathrm{a}$ and $4 \mathrm{~b}$. Zonal velocity variability predominantly occurs at lower frequencies, particularly at the semiannual and annual cycle and on interannual time scales (Fig. 4c). Those three frequencies are confined to vertical modes that form the gravest resonant equatorial basin mode (Brandt et al. 2016; Claus et al. 2016). On the contrary, the amplitude spectrum of meridional velocity (Fig. 4b) is neither as confined to certain distinct frequencies nor as large in amplitude as the zonal amplitude spectrum. However, the meridional amplitude spectrum is enhanced for frequencies between 7 and 12 cycles per year. Although lower vertical modes account for the strongest amplitudes, relatively high values are also observed toward higher baroclinic modes up to vertical mode 10. At higher frequencies, low-mode Yanai waves (vertical modes 2 and 3) show amplitudes comparable to the ones between 7 and 12 cycles per year.

The amplitude distribution in the frequency-vertical mode space for the meridional velocity therefore suggests that Yanai waves are responsible for the dominant observed intraseasonal variability. Interestingly, there is energy within the barotropic mode (mode 0) as well, but most of the energy is confined to vertical modes $2-5$. The variance spectra of both velocity components, respectively the sum of the squared amplitudes over all modes, are shown in Fig. 4c. Below 7 cycles per year (periods larger than 52 days) intraseasonal zonal velocity fluctuations exceed meridional ones. This relation is clearly reversed between 7 and 15 cycles per year, where meridional velocity variability is considerably larger than zonal velocity variability. Though differently obtained, both variance spectra shown in Fig. 3c (black curve) and Fig. 4c (blue curve) are reassuringly in good agreement.

\section{Seasonal and interannual variations of intraseasonal variability}

So far, the focus has been set on the mean statistics of intraseasonal variability derived from long-time moored velocity data, which are, as shown above, mainly associated with intraseasonal Yanai waves. In this section we will focus on the seasonal and interannual variations of intraseasonal variability both near the surface and in the deep ocean. A time series of specific kinetic energy of the meridional velocity averaged between depths of 20 and $50 \mathrm{~m}$ is derived from the available velocity dataset on the equator at $23^{\circ} \mathrm{W}$ (Fig. 5). Above approximately 20-m depth, velocity data from the upward-looking ADCP are usually contaminated owing to the surface 


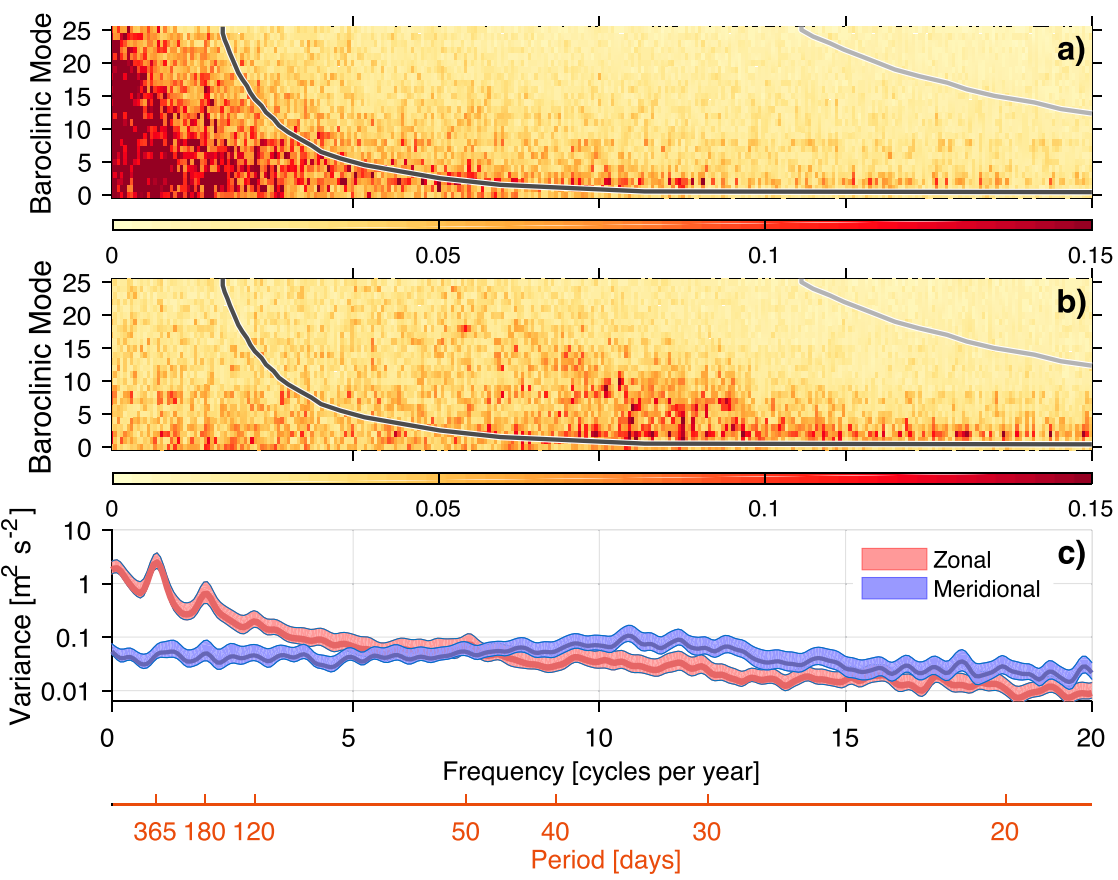

FIG. 4. Mean amplitude spectra $\left(\mathrm{m} \mathrm{s}^{-1}\right)$ of (a) zonal and (b) meridional velocity data for the barotropic mode (mode $=0$ ) and the first 25 vertical modes from 1000 permutations (see section $3 \mathrm{~b}$ for detailed description) and (c) variance spectra derived by summing the squared amplitude spectra in (a) and (b) over all barotropic and baroclinic modes. Also shown in (a) and (b) are the cutoff frequencies of equatorial Rossby waves (dark gray lines) and inertia-gravity waves (light gray lines). The shaded area around the integrated variance spectra in (c) represents the 95\% confidence range considering all 1000 permutations (see section $3 b$ for detailed description).

reflection of the signal. During two time periods the $\mathrm{ADCP}$ measurements on the equator at $23^{\circ} \mathrm{W}$ did not reach this depth range or the recovered data were defective causing a total of two interruptions in the time series from December 2002 to May 2005 (also including the time period when no mooring was installed) and from June 2006 to March 2008 (see also Fig. 1). Obviously, the existing data exhibit an annual maximum in boreal summer-typically in August-with maximum values occasionally reaching up to $0.1 \mathrm{~m}^{2} \mathrm{~s}^{-2}$. Although the timing of the annual maximum is robust, the year-toyear variations of the amplitude are remarkable (Figs. 1 and 5). In 2010 and 2013 the maximum values range between 0.03 and $0.04 \mathrm{~m}^{2} \mathrm{~s}^{-2}$, while each other year's maximum exceeds $0.06 \mathrm{~m}^{2} \mathrm{~s}^{-2}$. The observations also show a pronounced winter maximum at the beginning of the record, which is not comparably pronounced in the following winters. The climatology based on daily

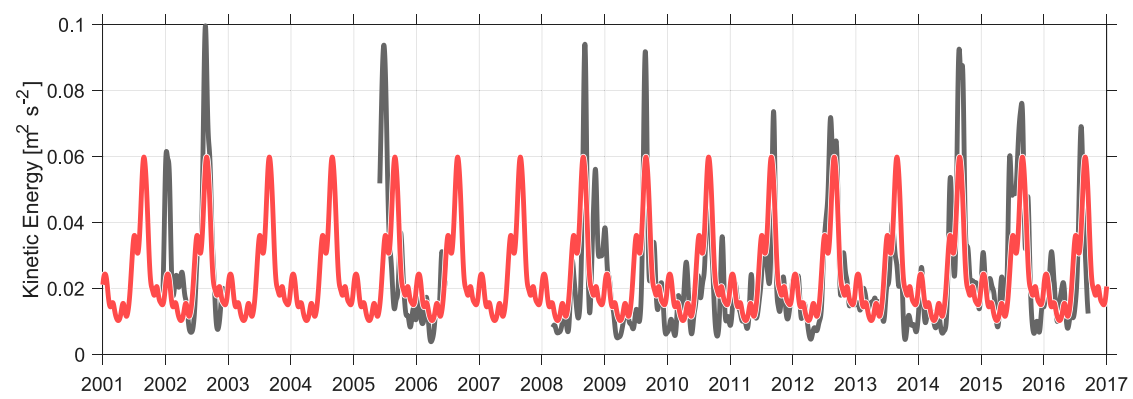

FIG. 5. Specific kinetic energy of the meridional velocity $(1 / 2) v^{2}$ vertically averaged between 20 and $50 \mathrm{~m}$ from the mooring on the equator at $23^{\circ} \mathrm{W}$ (gray) and the corresponding climatology (red). Tick marks along the time axis denote the beginning of the year. Time series are smoothed using a Hamming window of 30 days. 


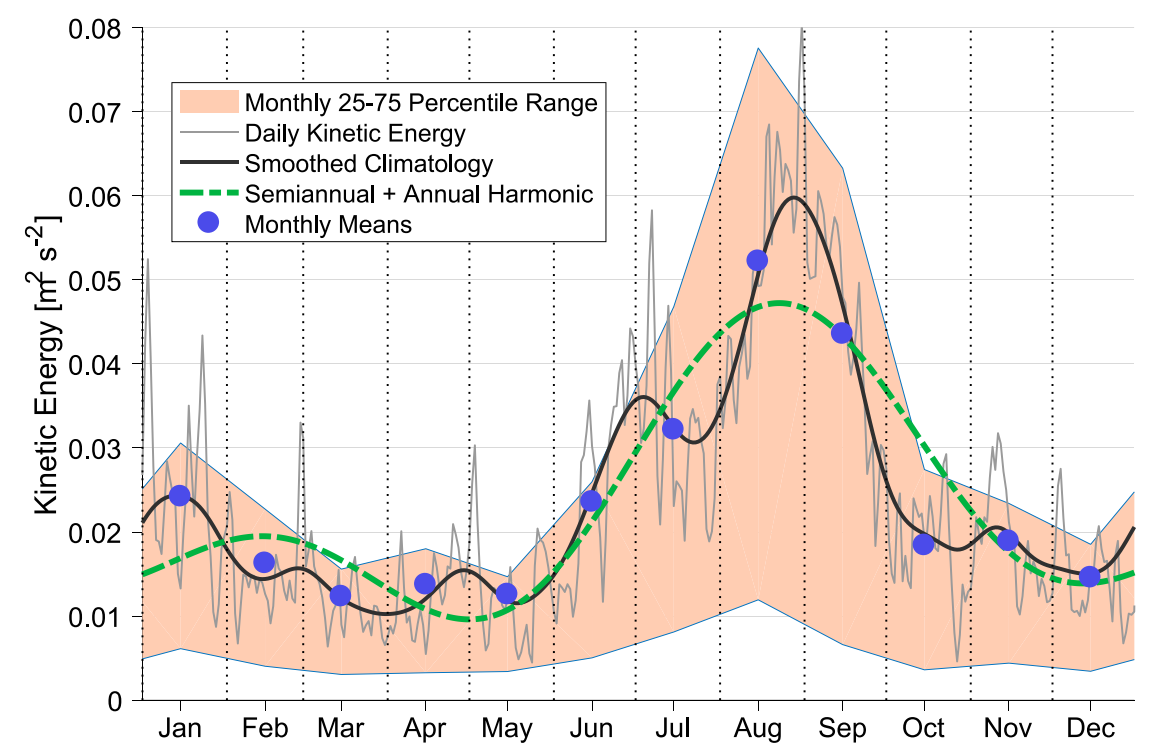

FIG. 6. Daily (gray) and monthly mean (blue dots) climatology of specific kinetic energy of the meridional velocity $(1 / 2) v^{2}$ vertically averaged between 20 and $50 \mathrm{~m}$ from the mooring on the equator at $23^{\circ} \mathrm{W}$. Tick marks along the time axis denote the middle of the month. Also shown is a linear combination of an annual and a semiannual harmonic that were fit to the daily data (dashed green) and a smoothed climatology (black) as well as the 25 th-75th percentile range derived from daily data (shaded).

annual averages exhibits a pronounced annual cycle peaking in August but also confirms a secondary maximum in January (Fig. 5; red curve). Both maxima vary strongly in their energy level from year to year.

A detailed look at the climatological cycle of intraseasonal specific kinetic energy within the near-surface layer on the equator at $23^{\circ} \mathrm{W}$ from Fig. 5 (Fig. 6) reveals that energy increases in June and eventually peaks in late August reaching values of up to 0.08 (daily climatology) and $0.06 \mathrm{~m}^{2} \mathrm{~s}^{-2}$ (30-day low-pass-filtered time series) before rapidly decreasing. In late December, specific kinetic energy increases again and peaks in January with values above $0.04 \mathrm{~m}^{2} \mathrm{~s}^{-2}$ and then quickly drops and remains at lower levels from March to May. Here, the seasonal cycle of intraseasonal energy between 20 and $50 \mathrm{~m}$ is approximated by a linear combination of a semiannual and an annual harmonic cycle both fit to the daily climatological cycle. The superposition of both cycles is able to explain a large fraction of the observed seasonal variability. It reproduces the temporal onset of the boreal summer maximum, while the amplitude is slightly underestimated but fails to reproduce the winter maximum in its onset and amplitude. Nevertheless, for a relatively simple combination of two harmonic cycles, the overall structure of the climatology is well captured.

The dominance of the seasonal cycle (particularly annual and semiannual variations) in the near-surface intraseasonal energy time series is further supported by an energy spectrum of specific kinetic energy derived from meridional velocities between 20 and $50 \mathrm{~m}$ (Fig. 7). The peaks at the annual and semiannual cycle are the main components of variability as both are significant at the $95 \%$ confidence interval from a first-order autoregressive (AR-1) process. Significant interannual variability is not observed, although the spectrum shows elevated variability at periods of about 2-3 years.

Considerable intraseasonal variability is also evident at greater depths between 200 and $2000 \mathrm{~m}$ (Figs. 1, 2, and 3a). A monthly full-depth climatology of anomalous specific kinetic energy of the meridional velocity (Fig. 8) exhibits not only a surface intensified annual cycle in the upper part of the ocean as already seen in Fig. 6 but also indication of a deep annual cycle and both downward and upward energy propagation. In the upper $200 \mathrm{~m}$, positive anomalies are present from July to October. Hence, during this time of the year, the specific kinetic energy exceeds the annual mean within this particular depth layer. Below $200 \mathrm{~m}$, the maximum of positive anomalies narrows in time with increasing depth to about $800 \mathrm{~m}$, where positive anomalies are observed between January and March of the following year. At these depths, anomalies cannot be anymore associated with local anomalies near the surface. Although Fig. 8 suggests downward energy propagation in the upper $800 \mathrm{~m}$, it cannot be directly inferred from it. Since the 


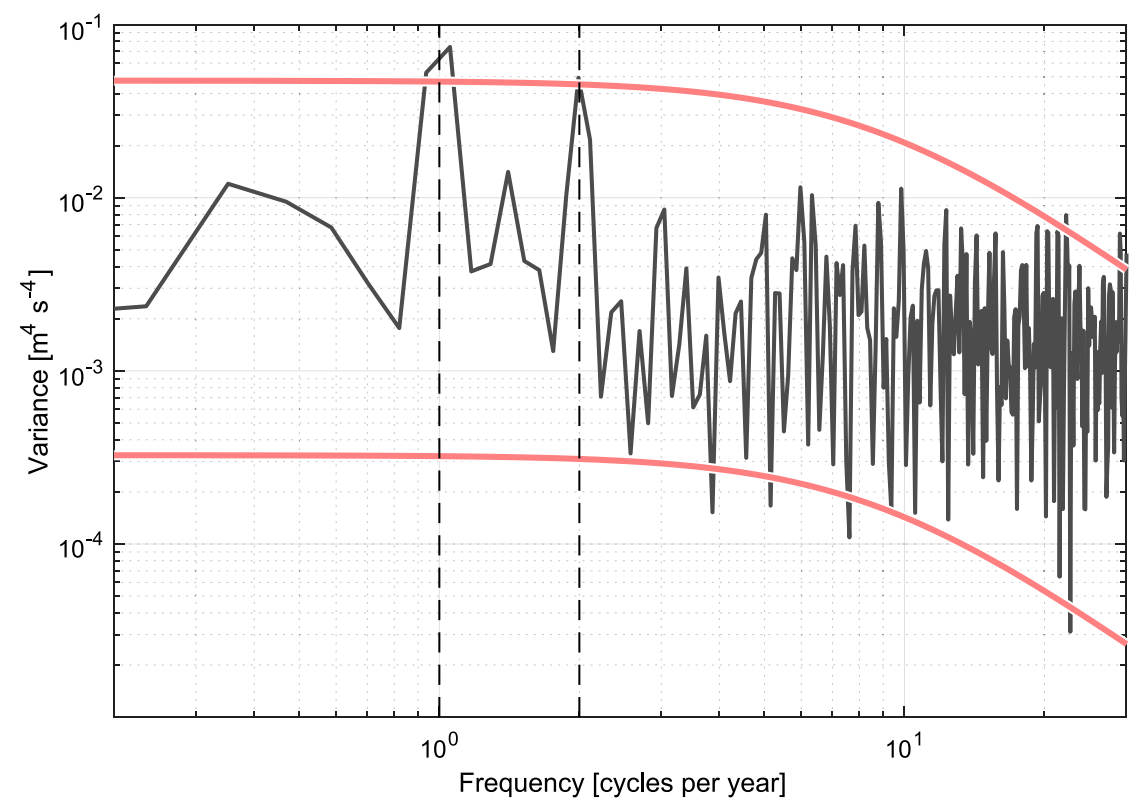

FIG. 7. Energy spectrum of specific kinetic energy of the meridional velocity $(1 / 2) v^{2}$, vertically averaged between 20 and $50 \mathrm{~m}$, from the mooring on the equator at $23^{\circ} \mathrm{W}$ (black) with the $95 \%$ significance interval (from an AR-1 process; red lines). The frequencies of the annual and semiannual cycles are marked by vertical dashed lines.

climatology is derived from velocity data at one mooring site and the variability is associated with Yanai waves that have an eastward group velocity, the energy at depth must originate from a source west of $23^{\circ} \mathrm{W}$ and has to propagate toward the mooring site along a Yanai beam as will be discussed in the next section. The depth and time of the year at which these beams reach the mooring site depends on their dominant frequency, their dominant vertical mode, and their generation depth, time, and longitude from which the beam starts its downward and eastward propagation.

Below $2000 \mathrm{~m}$, energy levels are considerably lower (Fig. 1). However, an annual cycle of anomalous specific kinetic energy can be identified down to about $2800 \mathrm{~m}$ (Fig. 8). Within this depth range, the observations indicate interference of downward and upward energy propagation likely originating at about $2500 \mathrm{~m}$ from July to September either reaching $1500 \mathrm{~m}$ from March to April or $2800 \mathrm{~m}$ in January of the following year. It is possible that the Mid-Atlantic Ridge acts as a local source of variability since it reaches up to depths of nearly $2500 \mathrm{~m}$ on the equator close to the mooring site at $23^{\circ} \mathrm{W}$ and might interfere with seasonal Kelvin and Rossby waves.

\section{Summary and discussion}

The availability of almost 15 years of partly fulldepth moored velocity data from the equator at $23^{\circ} \mathrm{W}$ enabled us to describe the main characteristics of oceanic intraseasonal variability including its downward radiation from near the surface into the deep ocean. We have shown that the near-surface layer $(20-50 \mathrm{~m})$ of the central equatorial Atlantic Ocean is characterized by a seasonal cycle of intraseasonal specific kinetic energy of the meridional velocity associated with zonally propagating TIWs exhibiting a pronounced annual maximum in August (Figs. 1, 5, and 6). Additionally, a relative maximum in January is revealed (Fig. 6), which is further supported by an energy spectrum of specific kinetic energy showing significant energy levels at annual and semiannual periods (Fig. 7). In agreement with $\mathrm{Wu}$ and Bowman (2007) and Perez et al. (2012), our observations show remarkable year-to-year variations with multiyear periods of lower TIW activity followed by years with higher energy levels (Fig. 5). However, the obtained energy spectrum of specific kinetic energy does not exhibit a significant peak at interannual time scales, although enhanced energy levels at periods of 2-3 years are observed (Fig. 7). It is likely that the time series is too short to capture significant interannual variability.

We further showed that the mean statistics of intraseasonal meridional velocity variability are characterized by the presence of enhanced variability at periods between 30 and 50 days both near the surface $(20-50 \mathrm{~m})$ and in the deep ocean down to about $2000 \mathrm{~m}$ (Fig. 3). Interestingly, the depth range of maximum power input 


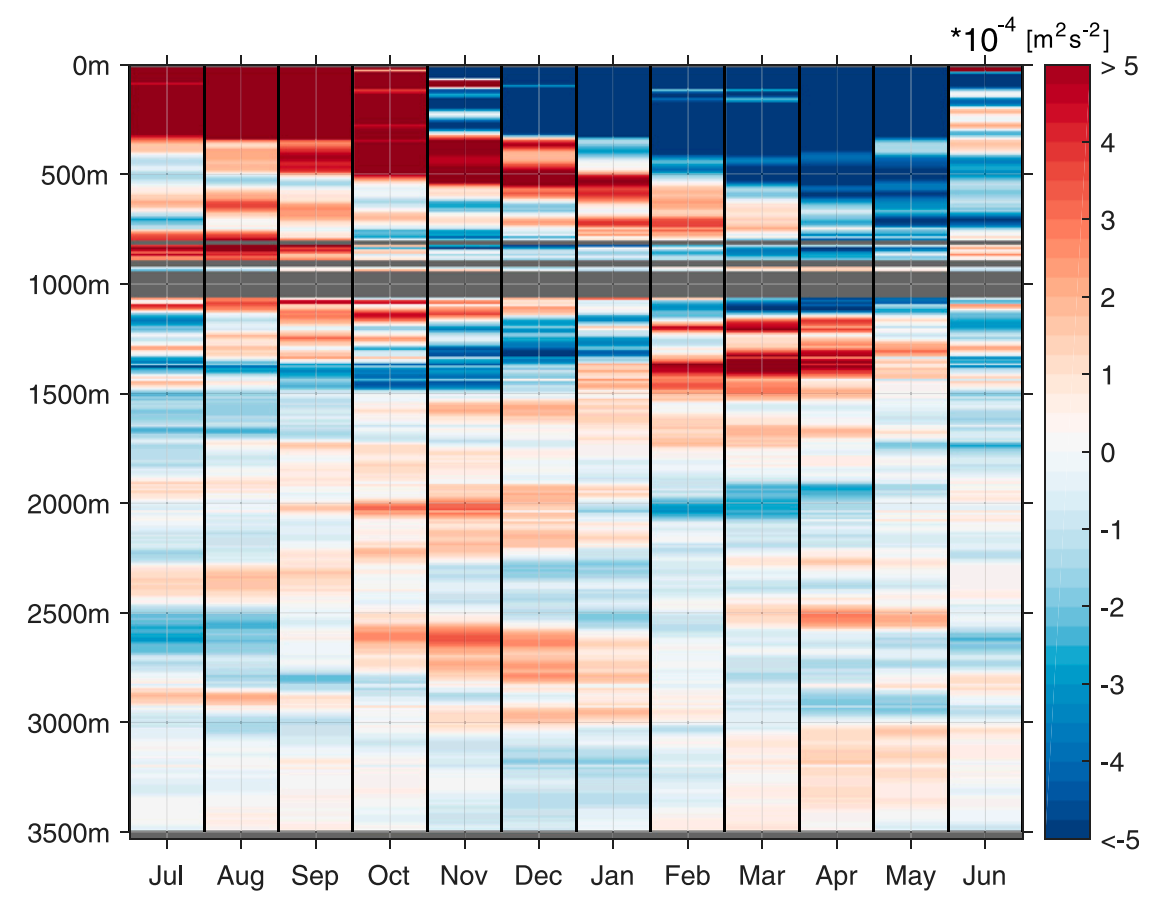

FIG. 8. Monthly climatology of anomalous (with respect to the mean at each depth) specific kinetic energy of the meridional velocity as function of depth (fit with an annual and a semiannual harmonic cycle at each depth) from the mooring on the equator at $23^{\circ} \mathrm{W}$. Months and depths with insufficient data coverage $(<90$ values per month over the whole time series) are marked gray.

from the DEIV into the EDJs as described in Claus et al. (2016, their Fig. 8) agrees with the depth range in which the intraseasonal frequency range is most distinct (Fig. 3d). The interaction of intraseasonal variability with the low-frequency EDJs was found to contribute to the maintenance of EDJs against dissipation (Greatbatch et al. 2018). According to Ascani et al. (2015) the DEIV is generated by the instability of the upper-ocean currents. Earlier modeling studies by D'Orgeville et al. (2007) and Ménesguen et al. (2009), as well as the theoretical work of Hua et al. (2008), suggested that a prescribed DEIV forcing (potentially fluctuations of the equator-crossing western boundary current) contributes to the generation and maintenance of EDJs. Both of these DEIV sources would be associated with eastward radiation of intraseasonal energy. The amplitude distribution in frequency-vertical mode space shows that most likely Yanai waves cause the observed intraseasonal variability; other equatorial wave types (i.e., equatorial Kelvin or Rossby waves) must play only a minor role (Figs. 4a,b). Note that according to the choice of method for the modal decomposition (i.e., the decomposition into standing vertical modes; see section $3 b$ ), inertia-gravity waves can be excluded at intraseasonal frequencies. However, this does not have to be the case in the framework of vertically propagating latitudinal modes (Philander 1978).

The superposition of several vertical modes (i.e., modes 2-5; Fig. 4b) results in distinct energy maxima at depth, which are suggestive of downward- and eastwardpropagating Yanai beams.

In the following, we will provide a discussion of possible processes and mechanisms relevant for the observed energy distribution of DEIV on the equator at $23^{\circ} \mathrm{W}$. On the basis of annual mean salinity and temperature data from the World Ocean Climatology (Levitus 1982) and the theoretical work on equatorial beams by McCreary (1984), a schematic showing the propagation of individual Yanai beams is constructed (Fig. 9; see also section 3c). It is assumed that in the equatorial Atlantic Yanai waves are mainly excited close to the surface by passing TIWs (assumed excitation depth: $40 \mathrm{~m}$ ), with a dominant period of 35 days (according to the most pronounced peak between 20 and $50 \mathrm{~m}$ in Fig. 3b) and form beams of energy that radiate downward and eastward. The angle of downward propagation only depends on the stratification (or buoyancy frequency) and the frequency of the Yanai wave [see (6)]. Here, five longitudes were chosen to trace Yanai beams forward (downward and eastward) in an attempt to quantify the vertical range at the mooring site 


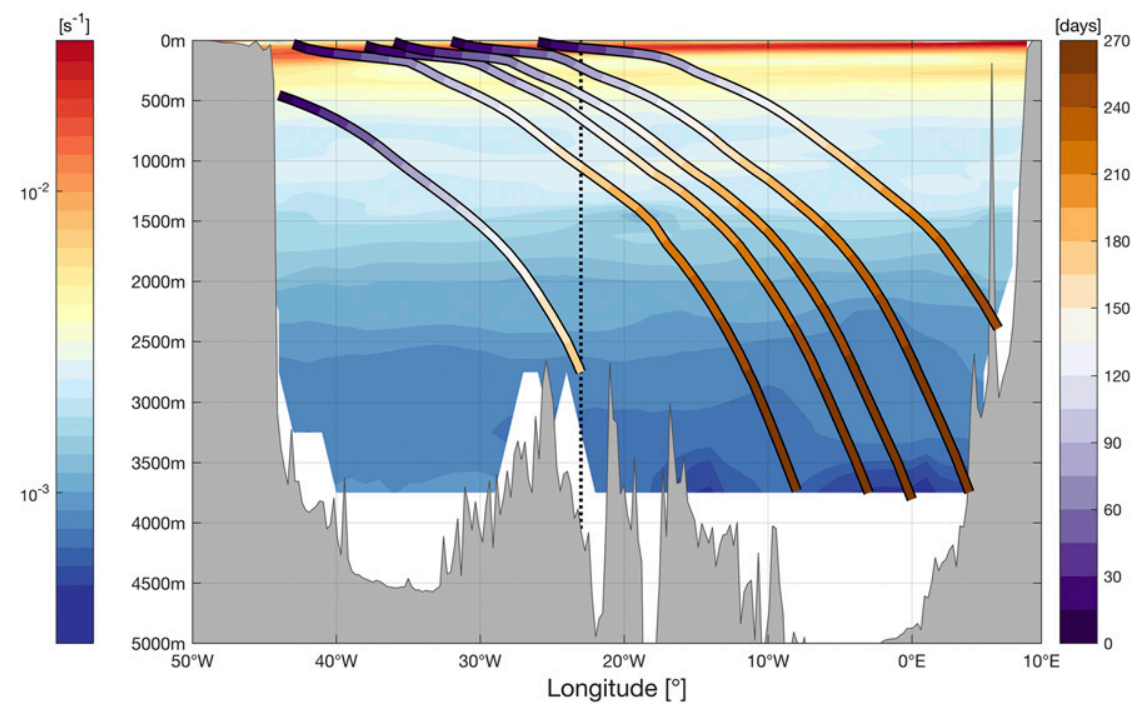

FIG. 9. Equatorial section of the mean buoyancy frequency (left color scale) derived from the World Ocean Climatology (Levitus 1982). Six exemplary Yanai beams calculated using the gravity wave speed of the second vertical mode and a period of 35 days are superimposed and colored according to their particular travel time since their excitation at a depth of $40 \mathrm{~m}$ or at the western boundary at $450 \mathrm{~m}$ (right color scale); see section $3 \mathrm{c}$ [(6)] for a more detailed description of the calculation of beams. The vertical dotted line marks the location of the $23^{\circ} \mathrm{W}$ mooring.

at $23^{\circ} \mathrm{W}$ on the equator possibly affected by Yanai beams generated near the surface at 40-m depth (Fig. 9). The apparent downward propagation of intraseasonal energy visible in the climatology of specific kinetic energy of the upper $800 \mathrm{~m}$ (Fig. 8) suggests that Yanai beams are excited almost simultaneously near the surface; their arrival time at the mooring position increases with depth (Fig. 9). The lower boundary of the DEIV at $23^{\circ} \mathrm{W}$ originating near the surface is thus limited by the distance to the westernmost extent of the near-surface maximum of intraseasonal energy at the equator. This was estimated to be about $40^{\circ} \mathrm{W}$ in the simulations of von Schuckmann et al. (2008) and would result in a lower DEIV boundary of about $800 \mathrm{~m}$ at $23^{\circ} \mathrm{W}$ (Fig. 9). However, Yanai beams generated at the surface close to the western boundary reach the mooring site below $1000 \mathrm{~m}$, which is in agreement with the observed deep intraseasonal variability (Fig. 3d).

The continuation of the Yanai beams to the east shows that the beams eventually reach the eastern part of the basin. At the eastern boundary, reflection into westward-propagating waves is not possible for frequencies in the interval between Rossby and inertiagravity waves. Instead, after approaching the eastern boundary, they have to propagate poleward as coastally trapped waves (see, e.g., Guiavarc'h et al. 2008).

These results suggest that intraseasonal wave energy that arrives at $23^{\circ} \mathrm{W}$ below approximately $2000 \mathrm{~m}$ via downward-propagating Yanai beams must originate at the western boundary below the near-surface (Fig. 9). The circulation at the western boundary is known to vary on intraseasonal time scales. Schott et al. (1993) showed that on the equator at $44^{\circ} \mathrm{W}$ variability of the alongshore component of velocity is most energetic at two different periods: between 60 and 80 days in the depth range of the North Atlantic Deep Water and between 25 and 35 days in the near-surface layer with a longer-period intraseasonal oscillation still observable. According to Fig. 9, downward-propagating Yanai beams with a period of 35 days, which arrive at the mooring position below about 2000-m depth, must originate from the western boundary in the depth range of the North Brazil Current, which crosses the equator near $44^{\circ} \mathrm{W}$ (Schott et al. 1998). Below $2000 \mathrm{~m}$, arrival times at $23^{\circ} \mathrm{W}$ within the seasonal cycle that are rather constant with depth require weak variations in the longitude of the origin of the Yanai beams at the western boundary, which is probably the case. Likewise, weak temporal variations in the seasonal maximum of intraseasonal variability of the deep western boundary current above $400 \mathrm{~m}$ are required. Fischer and Schott (1997) were able to show that the seasonal cycle of DWBC transport does exhibit a quite stable maximum in January/February, but because of the length of their moored velocity time series (about 3.5 years), uncertainty regarding this stability remains. 


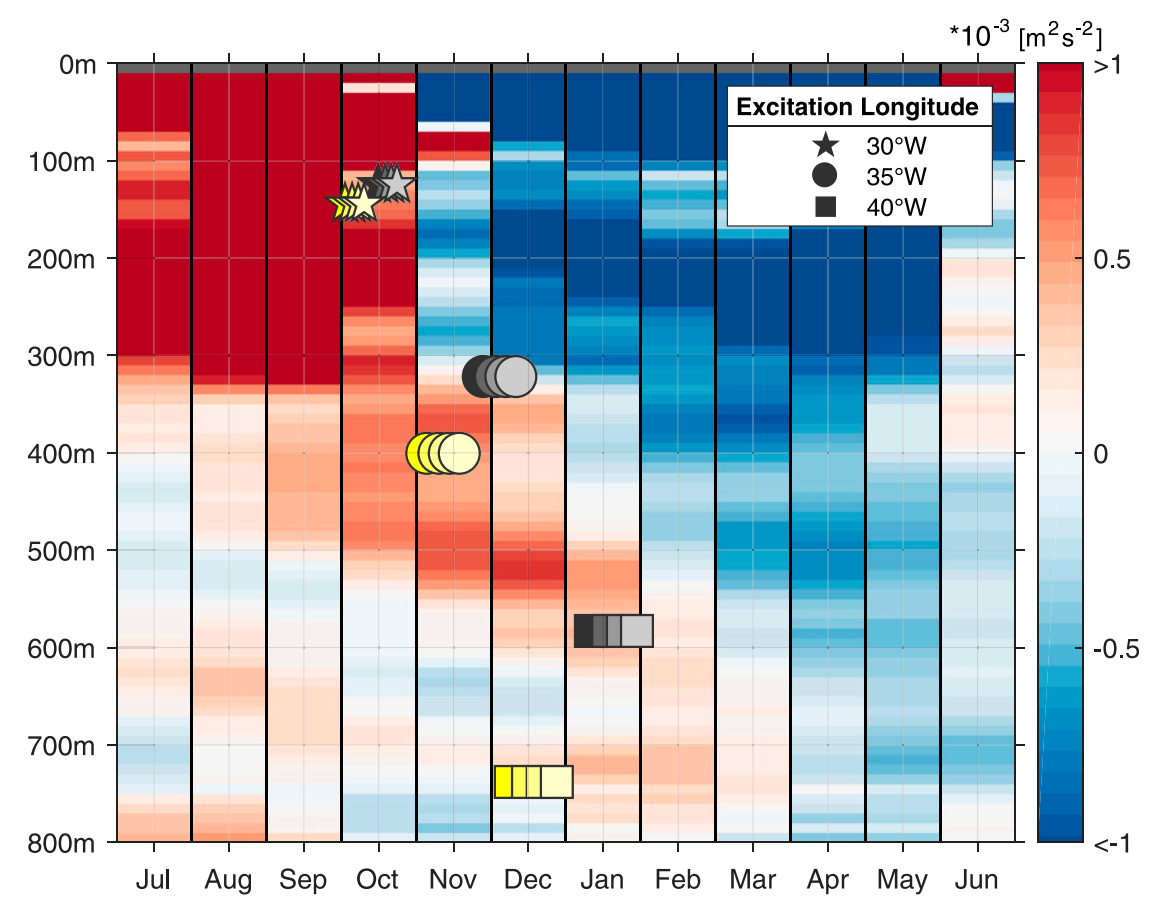

FIG. 10. As in Fig. 8, but for the upper $800 \mathrm{~m}$. Superimposed are arrival times and depths of three different Yanai beams at $23^{\circ} \mathrm{W}$ that were excited on $15 \mathrm{Aug}$ at $40-\mathrm{m}$ depth at $30^{\circ}, 35^{\circ}$, and $40^{\circ} \mathrm{W}$. Yellowish (grayish) colors correspond to a wave period of 35 (40) days. For each period, different Yanai beams were calculated by using the gravity wave speed of the first four vertical modes from left to right (1-4).

Below $2000 \mathrm{~m}$ on the equator at $23^{\circ} \mathrm{W}$, upward and downward energy propagation within the annual cycle of intraseasonal energy is indicated (Fig. 8). Additionally, the spectral characteristics of intraseasonal variability strongly change with depth. While in the depth range from 1000 to $2000 \mathrm{~m}$ intraseasonal waves with periods of 30-40 days dominate, below $2000 \mathrm{~m}$ a relatively sharp spectral peak emerges at a period just below 30 days (Fig. 3d). Here, in addition to a remote source of intraseasonal variability as described above, a local generation mechanism of intraseasonal variability due to the interaction of deep zonal flow with the MidAtlantic Ridge (e.g., see McPhaden and Gill 1987) may be possible as well. The topography of the Mid-Atlantic Ridge reaches the shallowest water depth of nearly $2500 \mathrm{~m}$ just west of the mooring position at around $25^{\circ} \mathrm{W}$ (Fig. 9). Kopte et al. (2018) showed that a deep annual cycle of zonal velocity with a maximum (minimum) from September to November (from February to April) is observed at $23^{\circ} \mathrm{W}$ below $2000 \mathrm{~m}$ (their Fig. 6), which might lead to the generation of seasonally varying DEIV.

In general, the exact characteristics of downward and upward propagation of intraseasonal energy are based on five variables: the excitation depth, time, and longitude, the dominant frequency, and the dominant vertical mode (or vertical wavelength) of the Yanai waves. To quantify the sensitivity of the travel time of a Yanai beam from its source to $23^{\circ} \mathrm{W}$ on the dominant vertical mode, frequency, and excitation longitude, separate Yanai beams are calculated using the gravity wave speeds of the first four vertical modes and two different Yanai wave periods (35 and 40 days). Figure 10 shows the time and depth at which the different Yanai beams arrive at the mooring position at $23^{\circ} \mathrm{W}$ that were excited on 15 August at $40-\mathrm{m}$ depth at $40^{\circ}, 35^{\circ}$, and $30^{\circ} \mathrm{W}$. Yanai beams calculated using the gravity wave speed of vertical modes $1-4$ arrive at $23^{\circ} \mathrm{W}$ at $720 \mathrm{~m}$ with a time difference of about 25 (27) days for a period of 35 (40) days. In comparison, a difference in period (i.e., 35 vs 40 days) introduces a time difference of about two months at $800 \mathrm{~m}$ (not shown). From approximately two years of moored velocity data on the equator at $35^{\circ} \mathrm{W}$ between 2004 and 2006 (Hormann and Brandt 2009) the seasonal maximum of near-surface specific kinetic energy between July and September is generally supported. However, the intraseasonal waves are presumably not excited exactly simultaneously, but within a temporal range of a few months, which introduces another uncertainty in the arrival time of wave energy at the mooring position. The energy distribution of the DEIV 
in space and time depends thus on a number of parameters associated with the generation and propagation of TIWs as well as with the background conditions.

The importance of the DEIV for the deep equatorial circulation has been pointed out in several studies (e.g., Hua et al. 2008; Ascani et al. 2015; Greatbatch et al. 2018), and the deep equatorial circulation possibly has an effect on climate (Brandt et al. 2011). Hence, a more realistic simulation of the DEIV with high-resolution general circulation models (GCMs) is required. This work presents observational evidence of the DEIV and characterizes its vertical distribution and statistics while also providing a discussion of possible generation mechanisms. The presented results provide a benchmark against which GCMs should be validated with respect to the representation of the DEIV in the equatorial Atlantic. In addition, these results also provide clues to understand possible differences between observed and simulated intraseasonal variability in the equatorial ocean.

Acknowledgments. This study was supported by the Deutsche Forschungsgemeinschaft as part of the Sonderforschungsbereich 754 (SFB754) "ClimateBiogeochemistry Interactions in the Tropical Ocean" and through several research cruises with R/V Meteor, R/V Maria S. Merian, and R/V L'Atalante by the German Federal Ministry of Education and Research as part of the cooperative projects RACE (03F0605B) and SACUS II (03F0751A) and by the European Union Seventh Framework Programme (FP7 2007-13) under Grant Agreement 603521 PREFACE project. Moored velocity observations were acquired in cooperation with the PIRATA project, with additional support for the moored profiler observations provided by the U.S. National Science Foundation. We thank the captains and crew of the R/V Maria S. Merian, R/V Meteor, and R/V L'Atalante as well as our technical group for their help with the fieldwork. We are grateful to two anonymous reviewers for their helpful comments and suggestions, which led to significant improvements of the manuscript.

\section{REFERENCES}

Ascani, F., E. Firing, P. Dutrieux, J. P. McCreary, and A. Ishida, 2010: Deep equatorial ocean circulation induced by a forceddissipated Yanai beam. J. Phys. Oceanogr., 40, 1118-1142, https://doi.org/10.1175/2010JPO4356.1.

,-- J. P. McCreary, P. Brandt, and R. J. Greatbatch, 2015: The deep equatorial ocean circulation in wind-forced numerical solutions. J. Phys. Oceanogr., 45, 1709-1734, https:// doi.org/10.1175/JPO-D-14-0171.1.

Athie, G., and F. Marin, 2008: Cross-equatorial structure and temporal modulation of intraseasonal variability at the surface of the tropical Atlantic Ocean. J. Geophys. Res., 113, C08020, https://doi.org/10.1029/2007JC004332.
Brandt, P., A. Funk, V. Hormann, M. Dengler, R. J. Greatbatch, and J. M. Toole, 2011: Interannual atmospheric variability forced by the deep equatorial Atlantic Ocean. Nature, 473, 497-500, https://doi.org/10.1038/nature10013.

- _ - A. Tantet, W. E. Johns, and J. Fischer, 2014: The Equatorial Undercurrent in the central Atlantic and its relation to tropical Atlantic variability. Climate Dyn., 43, 29852997, https://doi.org/10.1007/s00382-014-2061-4.

—, M. Claus, R. J. Greatbatch, R. Kopte, J. M. Toole, W. E. Johns, and C. W. Böning, 2016: Annual and semiannual cycle of equatorial Atlantic circulation associated with basin-mode resonance. J. Phys. Oceanogr., 46, 3011-3029, https://doi.org/ 10.1175/JPO-D-15-0248.1.

Bunge, L., C. Provost, B. L. Hua, and A. Kartavtseff, 2008: Variability at intermediate depths at the equator in the Atlantic Ocean in 2000-06: Annual cycle, equatorial deep jets, and intraseasonal meridional velocity fluctuations. J. Phys. Oceanogr., 38, 1794-1806, https://doi.org/10.1175/2008JPO3781.1.

Claus, M., R. J. Greatbatch, P. Brandt, and J. M. Toole, 2016: Forcing of the Atlantic equatorial deep jets derived from observations. J. Phys. Oceanogr., 46, 3549-3562, https://doi.org/ 10.1175/JPO-D-16-0140.1.

D'Orgeville, M., B. L. Hua, and H. Sasaki, 2007: Equatorial deep jets triggered by a large vertical scale variability within the western boundary layer. J. Mar. Res., 65, 1-25, https://doi.org/ 10.1357/002224007780388720.

Fischer, J., and F. A. Schott, 1997: Seasonal transport variability of the deep western boundary current in the equatorial Atlantic. J. Geophys. Res., 102, 27 751-27 769, https://doi.org/10.1029/ 97JC02327.

Garzoli, S. L., 1987: Forced oscillations on the equatorial Atlantic Basin during the seasonal response of the Equatorial Atlantic Program (1983-1984). J. Geophys. Res., 92, 5089-5100, https:// doi.org/10.1029/JC092iC05p05089.

Giarolla, E., P. Nobre, M. Malagutti, and L. P. Pezzi, 2005: The Atlantic Equatorial Undercurrent: PIRATA observations and simulations with GFDL Modular Ocean Model at CPTEC. Geophys. Res. Lett., 32, L10617, https://doi.org/10.1029/2004GL022206.

Gill, A. E., 1982: Atmosphere-Ocean Dynamics. Academic Press, 662 pp.

Greatbatch, R. J., and Coauthors, 2018: Evidence for the maintenance of slowly varying equatorial currents by intraseasonal variability. Geophys. Res. Lett., 45, 1923-1929, https://doi.org/ 10.1002/2017GL076662.

Grodsky, S. A., J. A. Carton, C. Provost, J. Servain, J. A. Lorenzzetti, and M. J. McPhaden, 2005: Tropical instability waves at $0^{\circ} \mathrm{N}, 23^{\circ} \mathrm{W}$ in the Atlantic: A case study using Pilot Research Moored Array in the Tropical Atlantic (PIRATA) mooring data. J. Geophys. Res., 110, C08010, https://doi.org/ 10.1029/2005JC002941.

Guiavarc'h, C., A. M. Treguier, and A. Vangriesheim, 2008: Remotely forced biweekly deep oscillations on the continental slope of the Gulf of Guinea. J. Geophys. Res., 113, C06002, https://doi.org/10.1029/2007JC004471.

Hormann, V., and P. Brandt, 2009: Upper equatorial Atlantic variability during 2002 and 2005 associated with equatorial Kelvin waves. J. Geophys. Res., 114, C03007, https://doi.org/ 10.1029/2008JC005101.

Hua, B. L., M. D’Orgeville, M. D. Fruman, C. Ménesguen, R. Schopp, P. Klein, and H. Sasaki, 2008: Destabilization of mixed Rossby gravity waves and the formation of equatorial zonal jets. J. Fluid Mech., 610, 311-341, https://doi.org/10.1017/ S0022112008002656. 
Hüttl-Kabus, S., and C. W. Böning, 2008: Pathways and variability of the off-equatorial undercurrents in the Atlantic Ocean. J. Geophys. Res., 113, C10018, https://doi.org/10.1029/2007JC004700.

Jochum, M., and P. Malanotte-Rizzoli, 2004: A new theory for the generation of the equatorial subsurface countercurrents. J. Phys. Oceanogr., 34, 755-771, https://doi.org/10.1175/15200485(2004)034<0755:ANTFTG > 2.0.CO;2.

,$- \ldots$, and A. Busalacchi, 2004: Tropical instability waves in the Atlantic Ocean. Ocean Modell., 7, 145-163, https://doi.org/ 10.1016/S1463-5003(03)00042-8.

Kopte, R., P. Brandt, M. Claus, R. J. Greatbatch, and M. Dengler, 2018: Role of equatorial basin-mode resonance for the seasonal variability of the Angola Current at $11^{\circ} \mathrm{S}$. J. Phys. Oceanogr., 48, 261-281, https://doi.org/10.1175/JPO-D-17-0111.1.

Levitus, S., 1982: Climatological Atlas of the World Ocean. NOAA Professional Paper 13, 173 pp.

McCreary, J. P., 1984: Equatorial beams. J. Mar. Res., 42, 395-430, https://doi.org/10.1357/002224084788502792.

McPhaden, M. J., and A. E. Gill, 1987: Topographic scattering of equatorial Kelvin waves. J. Phys. Oceanogr., 17, 82-96, https:// doi.org/10.1175/1520-0485(1987)017<0082:TSOEKW>2.0.CO;2.

Ménesguen, C., B. L. Hua, M. D. Fruman, and R. Schopp, 2009: Dynamics of the combined extra-equatorial and equatorial deep jets in the Atlantic. J. Mar. Res., 67, 323-346, https://doi.org/ 10.1357/002224009789954766.

Olbers, D., J. Willebrand, and C. Eden, 2012: Ocean Dynamics. Springer-Verlag, 704 pp., https://doi.org/10.1007/978-3-64223450-7.

Perez, R. C., R. Lumpkin, W. E. Johns, G. R. Foltz, and V. Hormann, 2012: Interannual variations of Atlantic tropical instability waves. J. Geophys. Res., 117, C03011, https://doi.org/10.1029/2011JC007584.

Philander, S. G. H., 1978: Forced oceanic waves. Rev. Geophys., 16, 15-46, https://doi.org/10.1029/RG016i001p00015.

Polo, I., A. Lazar, B. Rodriguez-Fonseca, and S. Arnault, 2008: Oceanic Kelvin waves and tropical Atlantic intraseasonal variability: 1. Kelvin wave characterization. J. Geophys. Res., 113, C07009, https://doi.org/10.1029/2007JC004495.

Qiao, L., and R. H. Weisberg, 1995: Tropical instability wave kinematics: Observations from the Tropical Instability Wave Experiment (TIWE). J. Geophys. Res., 100, 8677-8693, https:// doi.org/10.1029/95JC00305.

Scargle, J. D., 1982: Studies in astronomical time series analysis. II: Statistical aspects of spectral analysis of unevenly spaced data. Astrophys. J., 263, 835-853, https://doi.org/10.1086/160554.

Schott, F. A., J. Fischer, J. Reppin, and U. Send, 1993: On mean and seasonal currents and transports at the western boundary of the equatorial Atlantic. J. Geophys. Res., 98, 14353-14368, https://doi.org/10.1029/93JC01287.

- — , and L. Stramma, 1998: Transports and pathways of the upper-layer circulation in the western tropical Atlantic. J. Phys. Oceanogr., 28, 1904-1928, https://doi.org/10.1175/ 1520-0485(1998)028<1904:TAPOTU > 2.0.CO;2.

Steger, J. M., and J. A. Carton, 1991: Long waves and eddies in the tropical Atlantic Ocean: 1984-1990. J. Geophys. Res., 96, 15 3161-15 171, https://doi.org/10.1029/91JC01316.

von Schuckmann, K., P. Brandt, and C. Eden, 2008: Generation of tropical instability waves in the Atlantic Ocean. J. Geophys. Res., 113, C08034, https://doi.org/10.1029/2007JC004712.

Weisberg, R. H., and T. J. Weingartner, 1988: Instability waves in the equatorial Atlantic Ocean. J. Phys. Oceanogr., 18, 1641-1657, https://doi.org/10.1175/1520-0485(1988)018<1641: IWITEA $>2.0 . \mathrm{CO} ; 2$.

Wu, Q., and K. P. Bowman, 2007: Interannual variations of tropical instability waves observed by the Tropical Rainfall Measuring Mission. Geophys. Res. Lett., 34, L09701, https://doi.org/10.1029/ 2007 GL029719.

Yu, Z., J. P. McCreary, and J. A. Proehl, 1995: Meridional asymmetry and energetics of tropical instability waves. J. Phys. Oceanogr., 25, 2997-3007, https://doi.org/10.1175/ 1520-0485(1995)025<2997:MAAEOT>2.0.CO;2. 